\title{
The Salamanca Declaration in Practice: Inclusion in Europe 2008-2012
}

Tim I. Williams

University of Reading,

United Kingdom
Gaj Vidmar

University Rehabilitation Institute, Ljubljana, Slovenia

University of Ljubljana, Ljubljana, Slovenia

University of Primorska, Koper, Slovenia

Address all correspondence to Dr. Tim I. Williams, Institute of Education, University of Reading, London Road Campus, 4 Redlands Road, Reading, RG1 5EX. Email:

timothy.williams@reading.ac.uk 


\section{The Salamanca Declaration in Practice: Inclusion in Europe 2008-}

\section{2}

Educating all children in local schools (inclusive schooling) was agreed by the Salamanca declaration in 1994. Progress has been uneven with evidence from the USA that rural areas achieve higher rates of inclusion possibly due to socioeconomic factors. This paper considers whether individual jurisdictions in Europe are making progress, and which socio-economic factors may be relevant. A novel statistical analysis to identify outliers and economic and Social Progress Index data were used to determine likely sources of variation. There are significant differences across Europe both in the level of inclusion and in the progress towards inclusion. No economic or social indices predicted levels of inclusion. The most likely explanation for the one consistent outlier was a legislative one. The results are discussed with reference to data from the USA, and proposals are made for further analyses that might elucidate the reasons for differing levels of inclusion in education.

Keywords: inclusive education; special educational needs; special education; Europe; Salamanca declaration 
The Salamanca declaration of the United Nations (UNESCO, 1994, p. viii) affirms the "necessity and urgency of providing education for children, youth and adults with special educational needs within the regular education system". There are three reasons why this goal is considered important: 1) Segregating those who are different by reason of special educational needs or disabilities (SEND) represents a form of discrimination; 2) Special Education teachers often lack skills in teaching those areas of the curriculum that typically developing children might be expected to master; 3) students with SEND educated separately perform poorly in public examinations relative to their age peers. In this paper we examine the progress that has been made towards universal inclusive education for pupils with SEND using publicly available data with a view to both identifying both unusually good and poor practice. As a secondary aim, we sought to identify factors that might hinder the development of universal inclusive education by considering country level indicators of wealth, inequality and tolerance for minorities.

In Europe, the European Agency for Special Needs and Inclusive Education (EASNIE) recently reported that "all European countries are committed to working toward ensuring more inclusive education systems" (European Agency for Special Needs and Inclusive Education, 2017). EASNIE has published information supplied by governmental education authorities in each of the jurisdictions ${ }^{1}$ contributing to EASNIE. The data was first collected in 1999 and can be accessed through the website https://www.european-agency.org/. For the purposes of data analysis the clearest presentation is available in reports based on data collected in 2008, (European Agency

1. ${ }^{1}$ The term jurisdiction is used in this paper to refer to the level of government that determines and reports on education policy. Thus in Germany the Länder are responsible for education policy and therefore the extent of inclusion in schools. 
for Development in Special Needs Education, 2008), 2010 (European Agency for Development in Special Needs Education, 2010) and 2012 (European Agency for Development in Special Needs Education, 2012). In this paper we examine the evidence from the government sourced statistics that a greater proportion of children with disabilities and/or special educational needs are being educated in inclusive settings. A simple prediction would be that the proportion of children with special educational needs (SEND) educated in inclusive settings will rise over time across all the jurisdictions providing data. A secondary prediction would be that there will be increasing similarity between the jurisdictions taking part in EASNIE, as those jurisdictions approach the maximum possible inclusion of pupils with special educational needs.

\section{Monitoring policies}

The first question (increasing proportions of included pupils) can be tested by simple graphical examination of the data. The second question requires a more sophisticated approach to analyzing the data. The approach we use stems from the field of statistical analysis of quality as applied for instance to the performance of health care providers (e.g. Spiegelhalter, 2005). A naïve approach might be to rank the rates of inclusion, however, that provides little information about the distribution of the data and thus the relative rankings of the jurisdictions would not provide information about the importance of differences in rates of inclusion.

Spiegelhalter (2005) suggested that the use of analysis techniques which incorporated random variation allows for the identification of those jurisdictions that are performing exceptionally (either better or worse) as opposed simply ranking them. In particular Spiegelhalter (2002) suggested that funnel plots be used because they have the essential statistical property that observed values will be closer to the overall 
population mean for larger subsample populations. Further work suggested that the statistical approach itself needed some care because the observed distributions of the data differs significantly from the normal distribution, which is used in funnel plots either as the assumed distribution of the data or as the approximation to the binomial distribution. More recent work (Vidmar \& Blagus, 2014) demonstrated that when comparing small proportions with large denominator, such as the proportion of pupils with special educational needs in particular placements, the data tends to be overdispersed. The use of standard funnel plots may thus describe virtually all cases as outliers. Instead, Vidmar \& Blagus (2014) propose the use of the double square root plot, which optimizes the detection of outliers for both smaller and larger sample sizes.

In this paper our aims are to describe the changes over time in the proportion of pupils with SEN in inclusive education at both primary and secondary levels in the jurisdictions reporting to EASNIE, and to demonstrate differences between statistical approaches to identify outliers (both high and low levels of inclusion) with a view to exploring differences in inclusion policy. To our knowledge the analysis methods reported here have not been reported before in the education literature and we propose that they may enable monitoring agencies such as EASNIE to identify models of good practice and also cases where additional work may be required to meet the goals of the Salamanca declaration.

\section{Predictors of Inclusion}

In the USA the goal of inclusive education has been pursued for longer than in many other jurisdictions. Brock \& Schaefer (2015) investigated the extent of inclusion in one state (Ohio) to test the hypothesis that more urban areas would show increased segregation. Their findings confirmed earlier analyses of US state level data which had demonstrated that more urban areas and more populous areas showed increased 
segregation. They speculate that more rural areas and more sparsely populated do not have the resources to offer segregated education. An alternative explanation is that urban areas are more impoverished, and that therefore parents are unable to advocate for their children to the same extent as parents from wealthier districts. For the European data we sought to examine these hypotheses by using data from the World Bank which provides national level data on many economic variables and from the Social Progress Index which provides data on overall social inequality and on individual aspects of social attitudes such as acceptance of minorities and immigrants.

\section{Methods}

The numbers of pupils with special educational needs and the numbers of pupils with special educational needs educated in inclusive settings were extracted from the publications of EASNIE (European Agency for Development in Special Needs Education, 2008; European Agency for Development in Special Needs Education, 2010; European Agency for Development in Special Needs Education, 2012). The data for primary and secondary age levels is described separately.

Exploratory analysis of the data for primary and secondary age children using graphical representation was used to investigate the extent to which all jurisdictions could be described as showing an increasing level of inclusion over the period 20082012 (Increasing inclusion prediction). To identify outliers, statistical analyses of the primary and secondary age data were carried out. As described in Vidmar \& Blagus (2014), four methods for identifying outliers were used: Laney's p'-chart; Vidmar's double square root plot; Spiegelhalter's additive method; and Spiegelhalter's multiplicative method.

Laney's p'-chart estimates the actual variation in the data rather than assuming it. Initially all the proportions (i.e. of children with SEND who are in inclusive 
education) are used to determine a standard deviation assuming the binomial distribution. This standard deviation is used to calculate standardized values for each proportion ( $\mathrm{z}$ values), and then the standard deviation for the standardized proportions is derived. That is then used to calculate control limits, which are conventionally set at probabilities of 0.05 and 0.01 .

Spiegelhalter $(2002,2005)$ has been instrumental in developing two methods of constructing funnel plots: multiplicative and additive. In the multiplicative method the $\mathrm{z}$ scores are calculated as in Laney's p'-chart. Then the tenth and ninetieth percentile values are derived. Any z values outside the $10^{\text {th }}$ or $90^{\text {th }}$ percentile is set to the value of the $10^{\text {th }}$ or $90^{\text {th }}$ percentile respectively (process known as Winsorization). The distribution of the Winsorized $\mathrm{z}$ values is used to determine the over dispersion factor and, in turn, the control limits. In contrast, Spiegelhalter's additive model is based on multilevel modelling using method-of-moments meta-analysis techniques, which allows each proportion to generate a separate estimate for the real value, assuming a normal distribution of the observed values.

Vidmar \& Blagus advocate (2014) the double square root method instead. They start from an estimate of linear regression of the square root of the number (of children with SEND included in regular education) against the square root of the difference between the number included and the total number of children with SEND. The control limits are defined from the residuals of the regression. This differs from the other three approaches because it uses the actual numbers to derive the control limits as opposed to the proportions. In the results section we compare the four methods using a graphical illustration and a summary tabulation of the outliers defined by the four methods: Laney's p'; Spiegelhalter's multiplicative; Spiegelhatler's additive; and, Vidmar's double square root. 
Statistical analysis of the relationship between rurality, poverty and inequality indices used correlations to identify potential contributors and where considered appropriate the proportion of pupils with SEND was predicted using indices with significant correlations.

\section{Results}

Figure 1 shows the proportions of primary and secondary age pupils educated in inclusive settings during the studied period. The figure illustrates clearly that there is no simple increase in proportion included over the three time points of the surveys. Thus while Greece and Estonia show steadily decreasing proportions of pupils with SEN educated in inclusive settings, Latvia, Luxembourg, Malta and Scotland show steadily increasing proportions of pupils with SEN educated in inclusive settings. Other jurisdictions (Italy, Iceland, Portugal and Lithuania) have such high and stable proportions of pupils with SEN educated in inclusive settings that little improvement could be expected due to a ceiling effect. Most jurisdictions show no clear pattern of increase or decrease. The ranking order of individual jurisdictions is largely consistent for both primary and secondary age pupils (Spearman's correlation for the 2014 data $=$ $0.84, \mathrm{n}=19, \mathrm{p}<0.001)$.

Figure 1 about here

To detect outliers, four different approaches were adopted as described above. Figure 2 shows graphs of each of the methods of identifying outliers for the data from 2008 primary age cohort. Table 1 shows the numbers of outliers identified by each approach for each stage of education (primary, secondary) and each year of data (2008, 2010, 2012). The Spiegelhalter additive method results in more outliers than the other three approaches suggesting that the assumptions of this approach may not be appropriate for these data. In contrast Laney's p identifies only three outliers from the 
six datasets. Italy is represented twice in the 2010 and 2012 secondary data, whereas Denmark appears once as showing a low level of inclusion in the primary data set. Of the remaining two approaches Vidmar's method identifies Italy as an outlier in 5 out of six year-by-age combinations, in that a greater proportion of pupils with SEN are educated in inclusive settings than in the rest of the jurisdictions covered by the EASNIE data with the sole exception of the 2012 primary age data. Spiegelhalter multiplicative method identifies one, two or three outliers except for primary setting in 2010; it agrees with Vidmar's method in identifying Italy as having more pupils with SEN educated in inclusive settings then other jurisdiction, but also highlights Malta in one case as above the control limits, and unlike Vidmar's method also highlights some jurisdictions as having fewer pupils than generally expected educated in inclusive settings (France in two cases, Denmark; Greece and Belgium-Flanders in one case).

Figure 2 about here

Economic data was derived from the World Bank data set (GINI - World Bank, 2017a; rural population - World Bank 2017b) and the social inequity data was derived from the Social Progress Imperative website (Social Progress Imperative, 2017). Full details of the methods used to calculate the indices can be found on the relevant websites.

Pearson correlation coefficients show that there is a statistically significant relationship between proportion of pupils with SEND integrated at primary level and both GINI coefficient $(\mathrm{r}=0.49, \mathrm{~N}=17, \mathrm{p}<0.05)$ and rurality $(\mathrm{r}=0.48, \mathrm{~N}=18, \mathrm{p}<$ 0.05). The correlation coefficient for proportion integrated at primary level and social progress index (SPI) was non-significant $(\mathrm{r}=-0.35, \mathrm{~N}=16, \mathrm{p}=0.18)$. At secondary level, the correlation between proportion of pupils with SEND integrated and the GINI coefficient was significant $(\mathrm{r}=0.52, \mathrm{~N}=15, \mathrm{p}<0.05)$ but the correlations with the rurality 
index $(r=0.31, \mathrm{~N}=16, \mathrm{p}=0.25)$ and the SPI were not $(\mathrm{r}=0.13, \mathrm{~N}=14, \mathrm{p}=65)$. The SPI is however a composite measure and it might be more useful to examine lower level measures such as tolerance for minorities or immigrants which are also available on the SPI website. None of the correlations examined reached statistical significance: inclusion at primary school-tolerance for immigrants $(\mathrm{r}=-0.12, \mathrm{~N}=16, \mathrm{p}=0.65)$; inclusion at primary school tolerance of homosexuals $r=-0.28, \mathrm{~N}=16, \mathrm{p}=0.30$ ); inclusion at primary school - discrimination against minorities $(\mathrm{r}=0.04, \mathrm{~N}=16, \mathrm{p}=0.88)$; inclusion at primary school - religious tolerance $(\mathrm{r}=-0.09, \mathrm{~N}=16, \mathrm{p}=0.73$; inclusion at secondary school -tolerance for immigrants $(\mathrm{r}=-0.20, \mathrm{~N}=14, \mathrm{p}=0.49)$; inclusion at secondary school - tolerance for homosexuals $(r=0.03, \mathrm{~N}=14, \mathrm{p}=0.92)$; inclusion at secondary school - discrimination against minorities $(\mathrm{r}=-0.08, \mathrm{~N}=14, \mathrm{p}=0.79)$; inclusion at secondary school - tolerance of religion $(\mathrm{r}=-0.03, \mathrm{~N}=14, \mathrm{p}=0.93)$.

\section{Conclusions}

The EASNIE data do not indicate that the Salamanca declaration has led to consistent increases in inclusive education for pupils with SEND. Indeed the data reveal large differences in the proportion of pupils with SEND in inclusive settings across jurisdictions. Six jurisdictions have more than $90 \%$ of pupils with SEND in regular schools, whereas one jurisdiction consistently reports that less than $10 \%$ of its pupils with SEND are educated in inclusive settings. Four jurisdictions have shown clear increases in the proportion educated in inclusive settings. Two jurisdictions have shown substantial falls in the rates of inclusive education over this period. Italy alone stands out from the others, in that it achieves a level of inclusive education that is substantially different from the other jurisdictions.

The results from the four methods of identifying outliers show that the square root plot and Laney's method produce easily interpretable results. The Vidmar square 
root plot method indicates that Italy has the largest proportion of children with SEND educated in inclusive settings throughout 2008 to 2012 across both primary and secondary age groups, and that these proportions are statistically different from those of the other jurisdictions. Laney's p'-chart suggests that Italy is only an outlier for secondary education at two time points and that Denmark was only an outlier for one time point. Spiegelhalter's additive method describes much of the data as outliers, which implies that the method's assumptions are not met. Spiegelhalter's multiplicative method however, does not produce the stability of description that the square root method does. Thus for large-scale educational data where the distribution of proportions are over-dispersed as in this case, one might conclude that the square root method of Vidmar \& Blagus (2014) holds most promise for reliably identifying unusual cases.

None of the demographic, economic or attitudinal indicators appear to be related to the extent to which jurisdictions reporting to EASNIE are including pupils with SEND in local schools.

This paper is an attempt to both characterise the progress of inclusion across education systems in Europe and to understand the socioeconomic factors that may be at play in determining the extent of inclusion at both primary and secondary school level. It uses relatively novel methodologies to identify unusual cases robustly. One weakness is that the primary data are derived from that collected and published by EASNIE in its biennial reports. It is possible that the data is collected inconsistently. However, comparing data from different time points suggests that within jurisdictions it is possible to detect changes. Another criticism of this data is that the definitions of special educational need vary between jurisdictions (and also within a jurisdiction between the years). The argument advanced here does not require that the pupils with disability are the same population across jurisdictions, instead it is concerned with the principles 
behind the Salamanca declaration which determine that all children should be educated locally in the same provision so that there is no segregation of children with special needs, however defined.

As far as we are aware no other authors have attempted to analyse the extent to which different jurisdictions in Europe are implementing inclusive education policies. Instead authors have tended to concentrate on the attitudes of different participants (teachers, parents) to inclusion in different the different jurisdictions. Although this is useful at the level of individual schools, policy makers also need to consider how the internationally agreed process of inclusion is proceeding.

The use of statistical methods allows policy makers to analyse the extent to which policies are being followed, where data can be collected that identifies proportions of cases (in this case pupils). The validity of the statistical tests will of course depend on the way in which information is collected and its uniformity. Such considerations may affect long time series when legislative change may alter the numbers of pupils considered to have special needs. However, once identified as having special needs, the Salamanca declaration applies whatever the definition is adopted, and these methods depend on considering the proportions of those with special needs. Importantly making different assumptions about the distribution of the data may change the results of policy evaluations substantially and therefore necessitates an understanding of the data structure before proceeding to conclusions about the efficacy or otherwise of policies.

The EASNIE data reveals that there are what appear to be statistically significant differences between jurisdictions in the extent of inclusive education. Further it suggests that some jurisdictions are not increasing the proportion of children with SEND educated in inclusive settings. It is not clear why this should be when all 
jurisdictions have signed the Salamanca declaration. More worrying are the small number of jurisdictions that show a decreasing proportion of students with SEN accessing inclusive provision. Such jurisdictions might become the focus of increased effort by agencies concerned with improving the position of pupils with special needs. 
Brock, M. E., \& Schaefer, J. M. (2015). "Location matters: Geographic location and educational placement of students with developmental disabilities." Research and Practice for Persons with Severe Disabilities, 40(2), 154-164. DOI: $10.1177 / 1540796915591988$

European Agency for Special Needs and Inclusive Education (EASNIE) (2017). Agency Position On Inclusive Education Systems. Retrieved 5th January, 2017, from https://www.european-agency.org/sites/default/files/PositionPaperEN.pdf

European Agency for Development in Special Needs Education (2008). Special Needs Education Country Data 2008. Odense, Denmark: European Agency for Development in Special Needs Education.

European Agency for Development in Special Needs Education (2010). Special Needs Education Country Data, 2010. Odense, Denmark: European Agency for Development in Special Needs Education.

European Agency for Development in Special Needs Education (2012). Special Needs Education Country Data 2012. Odense, Denmark: European Agency for Development in Special Needs Education.

Social Progress Imperative. (n.d.). Retrieved June 22, 2017, from http://www.socialprogressimperative.org/

Spiegelhalter, D.J. (2002). "Funnel plots for institutional comparison.” Quality \& safety in health care, 11(4), 390.

Spiegelhalter, D. J. (2005). "Funnel plots for comparing institutional performance." Statistics in medicine, 24(8), 1185-1202. DOI: 10.1002/sim.1970

UNESCO. (1994). The Salamanca Statement and Framework for Action on Special Needs Education. Paris: UNESCO. 
Vidmar, G., \& Blagus, R. (2014). “Outlier Detection for Healthcare Quality

Monitoring-A Comparison of Four Approaches to Over-Dispersed Proportions."

Quality and Reliability Engineering International, 30(3), 347-362. DOI:

10.1002/qre. 1581

World Bank (2017a). Retrieved June 22, 2017, from

http://data.worldbank.org/indicator/SI.POV.GINI?end=2014\&start=1981\&view

$=$ chart

World Bank (2017b) Retrieved June 22, 2017, from

http://data.worldbank.org/indicator/SP.RUR.TOTL.ZS 
Table 1. Number of outliers identified by each method for the three sets of published data

\begin{tabular}{|c|c|c|c|c|c|c|}
\hline \multirow[b]{3}{*}{ Age group } & \multicolumn{6}{|c|}{ Year } \\
\hline & \multicolumn{2}{|c|}{2008} & \multicolumn{2}{|c|}{2010} & \multicolumn{2}{|c|}{2012} \\
\hline & Primary & Secondary & Primary & Secondary & Primary & Secondary \\
\hline Laney p' & 0 & 0 & 0 & $1 \uparrow^{\prime}$ & $1 \downarrow^{\mathrm{DK}}$ & $1 \uparrow^{\prime}$ \\
\hline $\begin{array}{l}\text { Spiegelhalter } \\
\text { additive }\end{array}$ & $2 \uparrow, 3 \downarrow$ & $8 \uparrow, 10 \downarrow$ & $2 \uparrow, 3 \downarrow$ & $8 \uparrow, 7 \downarrow$ & $9 \uparrow, 10 \downarrow$ & $8 \uparrow, 8 \downarrow$ \\
\hline $\begin{array}{l}\text { Spiegelhalter } \\
\text { multiplicative }\end{array}$ & $\begin{array}{l}1 \uparrow !, \\
1 \downarrow^{\mathrm{VL}}\end{array}$ & $1 \uparrow '$ & 0 & $1 \uparrow^{\prime}, 1 \downarrow^{F}$ & $\begin{array}{l}1 \uparrow M, 2 \downarrow^{D K}, \\
\text { DR }\end{array}$ & $1 \uparrow I, 1 \downarrow^{F}$ \\
\hline $\begin{array}{l}\text { Vidmar } \\
\text { double } \\
\text { square root }\end{array}$ & $1 \uparrow ।$ & $1 \uparrow ।$ & $1 \uparrow^{\prime}$ & $1 \uparrow^{\prime}$ & 0 & $1 \uparrow^{\prime}$ \\
\hline
\end{tabular}

Note: Upward arrows indicate the number of outliers above the control limits, downward arrows indicate the number of outliers below the control limits identified by each method in each year. The superscripts represent the jurisdictions: DK = Denmark; F = France; GR = Greece; $\mathrm{I}=$ Italy; $\mathrm{M}=$ Malta; $\mathrm{VL}=$ Belgium-Flanders. For reasons of clarity superscripts have not been used to identify jurisdictions identified as outliers by the Spiegelhalter additive method. 


\begin{tabular}{|c|c|c|c|c|c|c|}
\hline \multirow[b]{2}{*}{ Jurisdiction } & \multicolumn{3}{|c|}{ Primary } & \multicolumn{3}{|c|}{ Secondary } \\
\hline & 2008 & 2010 & 2012 & 2008 & 2010 & 2012 \\
\hline Italy & 99,9 & & 98,3 & 99,3 & & 99,5 \\
\hline Portugal & 93,2 & 92,3 & 96,6 & 100,0 & 92,3 & 98,9 \\
\hline Iceland & & 95,8 & 94,4 & & 95,8 & 93,0 \\
\hline Norway & 96,1 & & & 89,9 & & \\
\hline Malta & 74,6 & 85,7 & 98,6 & 100,0 & 85,7 & 93,0 \\
\hline Lithuania & 91,5 & 94,4 & 94,4 & 68,5 & 94,4 & 85,5 \\
\hline Spain & 81,3 & 89,8 & 89,3 & 84,9 & 89,8 & 84,1 \\
\hline Cyprus & 80,4 & 79,5 & 78,5 & 91,4 & 79,5 & 90,4 \\
\hline Scotland & 77,3 & 83,2 & 91,1 & 75,1 & 83,2 & 88,6 \\
\hline Switzerland & & 82,1 & & & 82,1 & \\
\hline Slovenia & 79,2 & 69,3 & 72,0 & & 69,3 & \\
\hline Ireland & 60,5 & 64,2 & 69,2 & & 64,2 & 100,0 \\
\hline Austria & 59,0 & 63,3 & 65,5 & 54,5 & 63,3 & 54,3 \\
\hline Luxembourg & 42,2 & 63,1 & & 70,5 & 63,1 & \\
\hline Estonia & 84,3 & 59,2 & 32,7 & 57,0 & 59,2 & 29,8 \\
\hline Finland & 47,9 & 50,2 & 50,7 & 55,6 & 50,2 & 60,3 \\
\hline Czech Repbulic & 49,1 & 53,6 & 59,3 & 47,2 & 53,6 & 51,0 \\
\hline Poland & & 58,3 & 54,7 & & 58,3 & 32,7 \\
\hline Hungary & 52,4 & 55,2 & 58,8 & 28,3 & 55,2 & 43,1 \\
\hline Slovakia & & & 36,6 & & & 44,1 \\
\hline Netherlands & 37,8 & 41,4 & 39,1 & 25,0 & 41,4 & 37,0 \\
\hline France & & 41,8 & 41,0 & & 41,8 & 13,8 \\
\hline Greece & 77,7 & & 5,6 & 44,9 & & 3,2 \\
\hline Latvia & 9,1 & 19,0 & 28,7 & 5,3 & 19,0 & 19,9 \\
\hline Belgium - Vlaams & 11,9 & 14,1 & 14,6 & 12,2 & 14,1 & 19,6 \\
\hline Denmark & 6,3 & 16,2 & 5,1 & 4,5 & 6,2 & 2,2 \\
\hline
\end{tabular}

Figure 1 Bar chart of the proportions of pupils with SEND integrated into local schools at primary and secondary ages using data from the EASNIE reports. The length of the dark grey bar in each cell is determined by the proportion of pupils with SEND that are educated in local schools - the actual proportion is shown as a percentage in black numerals. The jurisdictions are listed in decreasing order of average proportion across all the reporting years and both ages. Light grey background indicate downward trend by more than 1/10 over two-year period. 
Laney $\mathrm{p}^{\prime}$-chart

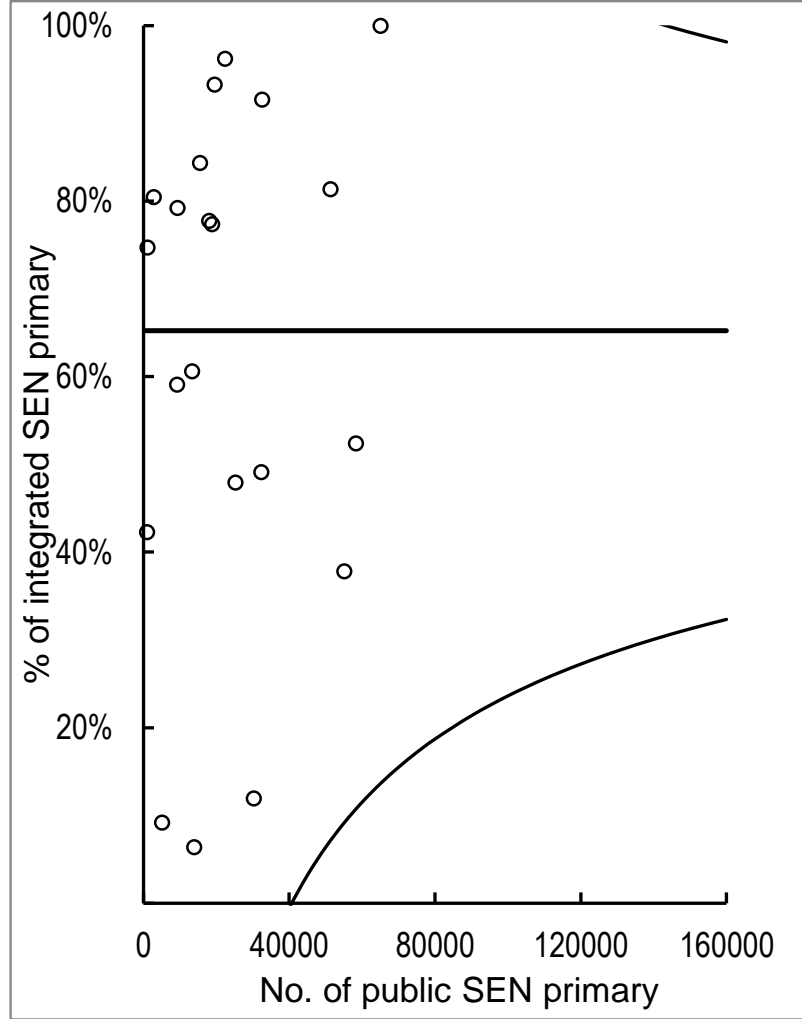

Spiegelhalter multiplicative funnel plot

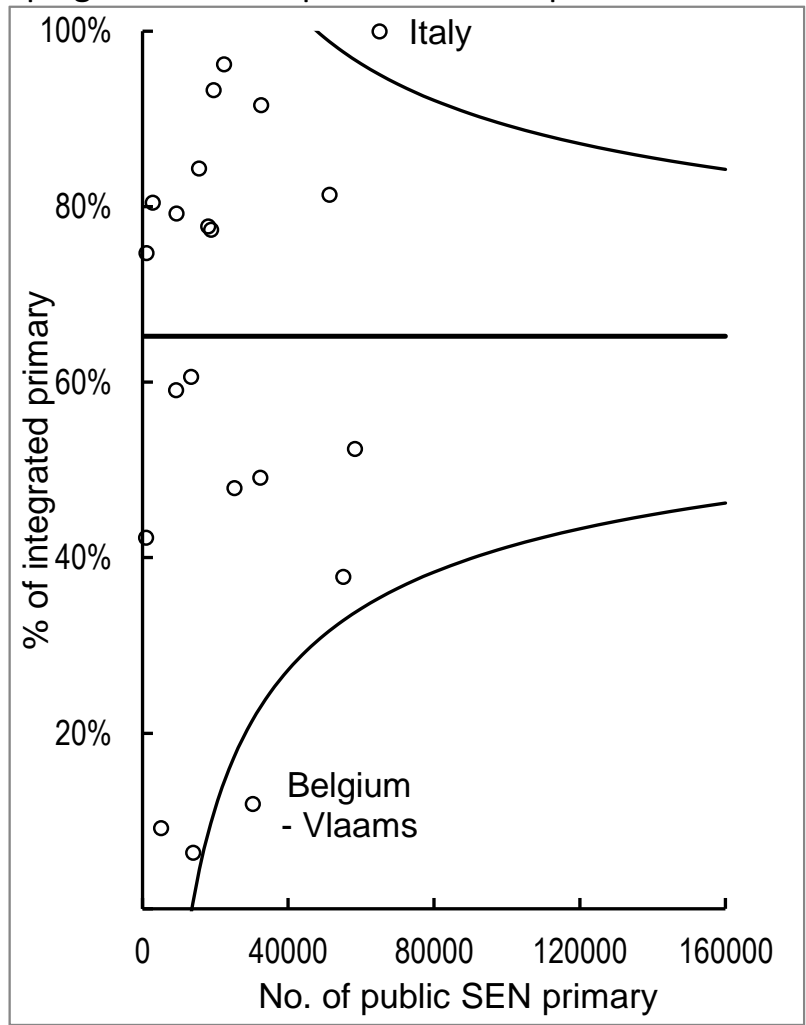

Vidmar double square root chart

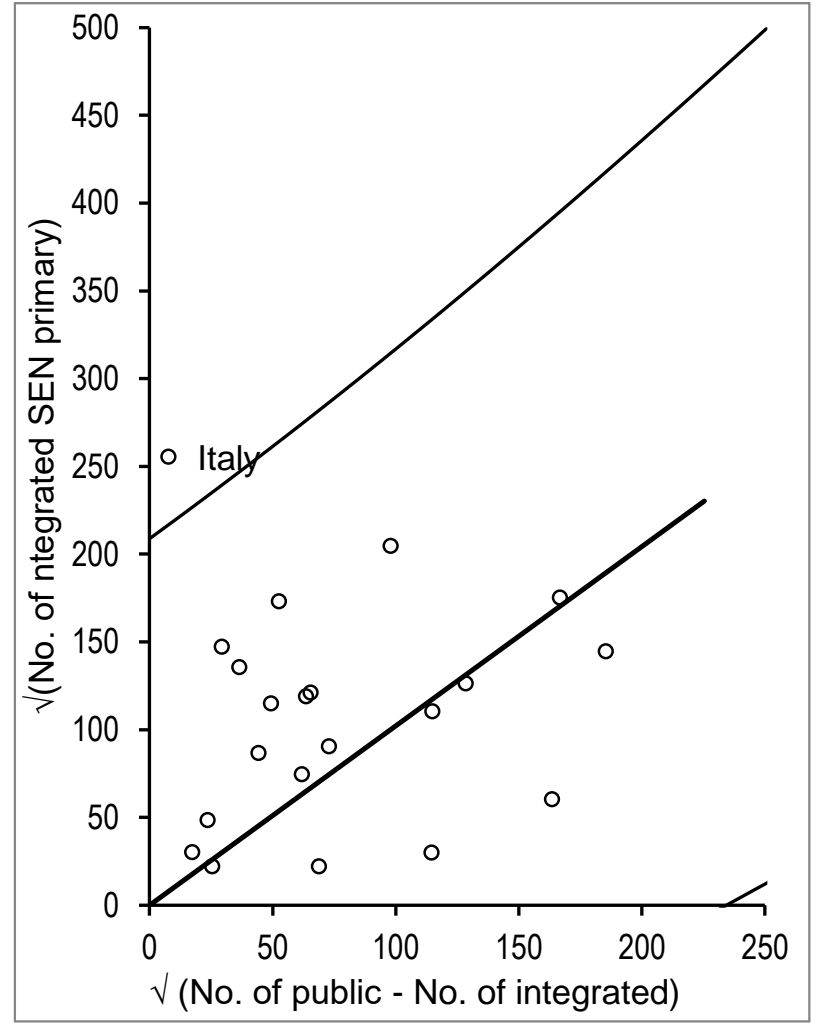

Spiegelhalter additive funnel plot

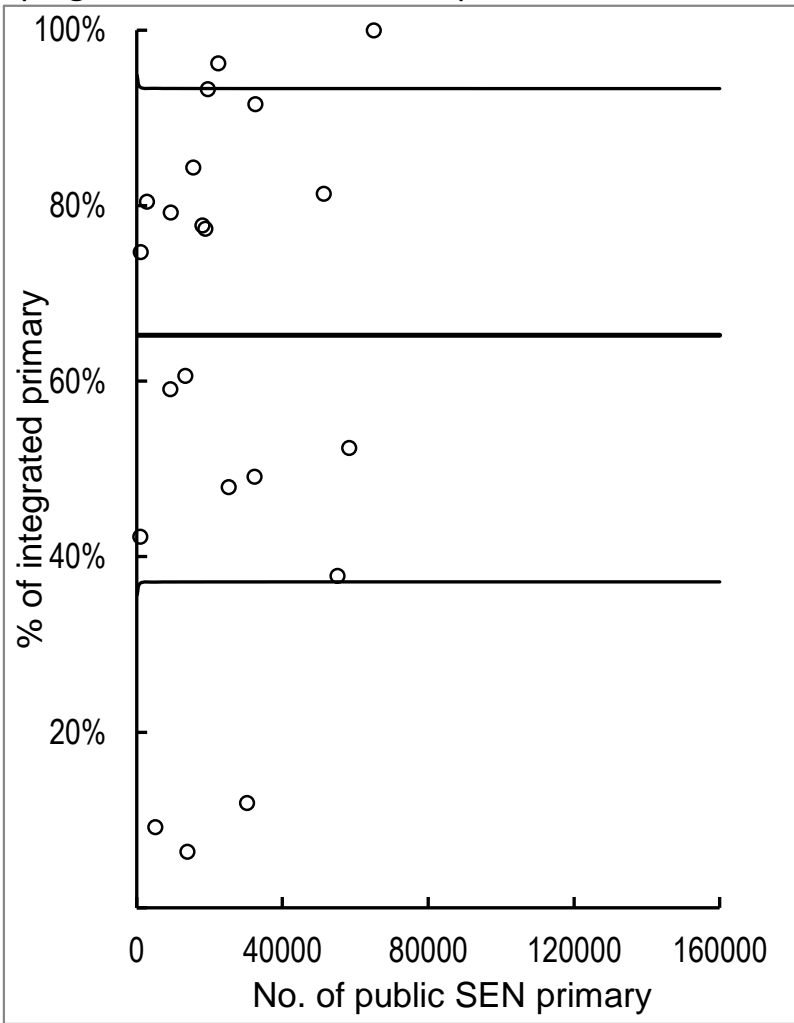

Figure 2 The effect of different methods on identifying outliers. The dataset used is the primary age data published by EASNIE on the number of children with special educational needs educated in inclusive settings in 2008. The thick centre lines represents the overall average across all countries; the top and bottom lines represent the control limits. Axis labels: public SEN primary $=1^{\circ}$ age children with SEN; Integrated SEN primary $=1^{\circ}$ age children with SEN in inclusive setting. 